\title{
A Tool for Measuring Organization Performance using Ratio Analysis
}

\author{
Adekunle R. Onaolapo' ${ }^{1}$, Elijah Adeyinka Adedeji ${ }^{2}$ \\ ${ }^{1 \& 2}$ Ladoke Akintola University of Technology, Ogbomoso. Oyo State. Nigeria \\ yinkaelijah@gmail.com
}

\begin{abstract}
Ratio analysis has served as a veritable means of monitoring, measuring and improving performance in an organization. Hence, the study examines a tool for measuring organization performance using ratio analysis. It also ascertains the relevance of internal and external financial reports during ratio analysis for the purpose of establishing key relationships and results in order to appraise financial performance. The study confirmed that there is significant relationship between ratio analysis and organizational performances as well as financial ratios highlight the importance of effective management of an organization. Based on the findings of this study, it was recommended that financial ratios should be computed periodically to reveal areas of strengths and weaknesses, as well as, ratio analysis should be used to measure performance in terms of profitability.
\end{abstract}

Keywords: Ratio analysis, Performance, Organization, financial Ratios, Management.

\section{INTRODUCTION}

The purpose of preparing the financial statements of a company is to convey information on the overall performance and the state of affairs of such an organisation to all interested parties. Besides, users of these financial statements in such a way as to reveal the financial strengths and weaknesses of such an organisation in order to form an opinion as regard her goingconcern. However, ratio analysis is one of the ways through which the financial statements could be interpreted. While ratio analysis is also a method used by financial managers and investors alike to compare a company's financial structure, conditions and performances with standards prevailing in such industry for the purpose of high-lighting improvement or deterioration in the trend of the business performance. Lucey (1988) defined ratio analysis as the systematic products of ratios from both internal and external financial reports so as to summarize key relationships and results in order to appraise financial performance.

More so, ratio analysis could serve as a practical means of monitoring and improving performance and it could be enhanced when:

- Ratios are prepared regularly and on a consistent basis so that trends can be highlighted and changes investigated.

- Ratios prepared for and individual firm can be compared with facilitated when the firm has ready access to comparative ratios prepared in a standard manner.

- Ratios are prepared showing the inter-locking and inter-dependent nature of the factors which contribute to financial success.

Nevertheless, ratio analysis utilizes figures that routinely appear in the financial statements for a period of several consecutive years, (that is 5years to 10years). One calculated, the ratio may be compare with external industry standards and with internal goals and budgets of the organisation in order to detect trends and estimates, improvement and stability of the measure conditions. Finally, it must be emphasized that ratios must be compared with some prevailing standards, because it cannot in itself convey any useful information. 


\section{STATEMENT OF THE PROBLEM}

Managerial decision is one of the keys to success in an organisation. And as such, management of a given organisation makes decision based on financial performances prevailing in such establishment. In arriving at such decisions, the management tries to focus their attention on two basics of comparison which are as follows:

Current performances are compares with the records of the part years in the organisation at least five (5) year's period.

Current performances are compared with that attested performances in other similar organizations.

As a result of this exercise, in-estimable short comings may arise which could force management to take drastic steps/decisions that could make or mar the organisation. Also, problems may arise when an attempt is made to compare the ratio of one business with those of other organisation, and these could arise as a result of different accounting basis and the aftermath result could not be relied upon.

Moreover, problem(s) associated with effect of inflation are always being ignored and the resultant ratios are of limited value. As a result of the following, the aforementioned shall be examined in the course of this research work.

\section{OBJECTIVE OF THE STUDY}

The broad objective of the study is to analysis how ratio analysis can be used to measure performance of an organisation. Also the following specific objectives will be examined in the course of this study:

- To critically analyse the financial statement and evaluate the performance of the company through ratios to ascertain whether resource are optimally and efficiently utilized.

- To evaluate the historical activities of the company such that a projection into the future can be made thereby improving management decision.

- To analyse the problems associated with the use of financial ratio analysis and proffer possible solutions.

- To identify the importance of financial ratio analysis to every use group.

- To analyse how financial ratio analysis can assist management to detect the various strengths and weaknesses of an organisation.

\section{RESEARCH QUESTIONS}

The following research questions shall be examined during this study:

- Do you use financial ratios as a measurement of management performance

- Does the management of this company apply financial ratio in making decisions that affect the company?

- Does ratio analysis help management in taking effective decisions?

- Do you agree that financial ratio reveal strengths and weaknesses of an organisation?

- Does the interpretation of ratios help to determine whether the activities of the company have been effectively managed?

- Does interpretation of ratio yield positive results? 


\section{RESEARCH HYPOTHESES}

The following hypotheses shall be tested during this research work:

- Ho: Financial ratios do not highlight the importance of effective management of an organisation.

- Hi: Financial ratios highlight the importance of effective management of an organisation.

\section{LITERATURE REVIEW}

Ratio according to Garbutt (1972) is one number expressed in terms of another. It is defined in the Oxford Dictionary as the relationship between two amounts determined by the number of times one is contained in the other. By the use of ratio analysis techniques, it is possible to facilitate comparison of significant figures, by expressing their relationship in the form of ratios or percentages, thus enabling the accounts of a business to be interpreted by bringing into focus salient features contained in the financial statements.

Financial ratios are employed to denote past trends, compare present performances and may give an indication to future trends, performances or operations of a company and thus acts as signposts for plans and policies. It could be deduced from the above that ratios serves as practical means of monitoring and improving performances of a company (Lucey, 1988).

\section{BASIS OF COMPARISON}

Financial ratio as an index is more useful when it is compared with another index. The basis of comparison includes the following;

- Intra-Firm comparison or previous year basis.

- Inter-Firm comparison or similar business basis.

- By basis of ratio established by the management (standard).

\section{Objective of inter-firm comparison}

Garbutt (1972) stated that inter-firm comparison is intended to show the management of each firm:

- How its profitability and productivity compare with that of other firms in the same industry.

- In what respects the firm is weaker or stronger than its competitors.

- What specific questions of policy or performance should be tackled if the firm's profitability and productivity are to be raised?

\section{Benefits of inter-firm comparison}

Garbutt (1972) also noted that the information emerging from comparative surveys may throw new light on points such as follows;

- The actual rate of return on capital being achieved in the industry

- The industry's cost structure

- The main areas of weaknesses and strengths found in a company

- The areas where there seem be 'bottleneck' factors inhibiting economic growth.

- Comparison may also provide realistic quantitative assessments of the scope for increased productivity and efficiency in the industry.

\section{The basis of ratios established by the management (standard)}

$\underline{\text { Financial ratio for the current period may be compared with standard ratios established by the }}$ 
management. This basis follows, budgetary analysis whereby budgeted ratios are compared with actual ratios as calculated from figures in the financial statements and variances identified. The variances that occur (whether favourable or adverse) will help the management in interpreting the performances of the company which will in turn aid in predicting the company's future performance. - Lucey, 1988.

\section{Interested parties to the accounts and financial ratios}

The fundamental purpose of financial reporting is to communicate economic measurement of information about the resources and performances of an organization useful to those having reasonable right to such information. (SAS 2, 1987). Accounting information (and thus ratios calculated) of a business is required by a variety of users. According to the statement of Accounting Standard (SAS2, 1987) there are many users, which can be grouped into two, showing clearly why they need such information (Aghoroh, 1999). The interested parties to financial statements and ratios are grouped into two as follows:

- Internal users.

- External users.

\section{Classification of financial ratios}

Three are various way of classifying ratios; this depends on the information need of the analyst of the financial statements. Ratio can be classified in terms of their data source; hence, we have the following classifications:

\section{Balance sheet ratio}

These are ratios calculated using two related figures from the balance sheet.

\section{Profit and loss account ratio}

These are ratios calculated form related figure in the profit and loss accounts.

\section{Inter statement ratios}

An inter statement ratio is calculated by relating items in both the balance sheet and profit and loss account.

Garbutt (1972) noted that ratios could be loosely grouped into the following and as a measure of profitability, liquidity or asset use solvency. Another possible and more acceptable method of classifying ratios is according to the financial activity (functions). This method helps to analyse and gives an overview of information required by various parties interested in the company's financial reports. For example, creditors are interested in the liquidity position of a company; hence, they consider the liquidity ratios. Shareholders are concerned about the net worth and profitability, as a result they monitor the profitability ratios.

Ratios used to measure the financial activity of a company can be grouped into four in respect of this research work:

Profitability and Efficiency.

Short term solvency and liquidity.

Long term solvency and liquidity/capital structure.

Potential and growth investors' ratio.

\section{Importance ratio analysis}

Ratios are effective tool of management in the provision of information and data needed in planning and determining the efficiency of management for a particular period. Ratios are also 
used to established relationship and trends in the financial statements. Ratios are important and useful to various user groups as viewed from the following perspective.

\section{Trend analysis}

Ratios enable users of financial statement determine whether the financial position of a company is improving or deteriorating over time. The importance of trend analysis is that the analyst knows whether the company is operating on a favourable level or not.

\section{Liquidity position}

According ratios enables various user groups to know or determine the ability of a company to meet its long or short term obligation.

\section{Inter-firm comparison}

Ratios are often compared among companies in the same industry. This is important because it enables the management of a company to know the position of the company in the industry and among competitors.

\section{Profitability}

The ratios also help to determine the overall profitability of a company. This helps management to determine whether the company can meet its short and long term debts and still maintain optimum return.

\section{Operating efficiency}

This shows how effectively the management utilizes the assets and how the assets are used in generating sales and revenue.

\section{Advantages of ratio analysis}

As stated earlier, there are various techniques which could be employed in the interpretation of the financial statements. These techniques include the straight forward criticism, ratio analysis and movement of funds statements (cash flow statements). The ratio analysis technique has the following advantages over the other techniques.

- The ratio analysis technique provided a standard through which ratios can be compared at any point in time.

- The ratios are easy to compute since figures used in computing are picked from the financial statements.

- Formulates used in calculating ratios are uniform. That is, the formulas are the same all over.

- Ratios could be combined with other measures, which are also used in evaluating performance of an organization.

\section{METHODOLOGY}

The population of study is the staff of PZ CUSSONS PLC, an organization that is reputable for efficiency as a result of management integrity. The population shall be chosen among the staff of finance, marketing and production departments of the organization and they shall constitute the sample for the survey. For the purpose of this research work selected respondents were draw from the total population through simple random sampling. This procedure gives opportunity to all respondents to be selected evenly. Staffs were randomly selected from their departments and given the questionnaires. In the process, only a very few of them collected and filled the questionnaire, while countable number of them allowed to be interviews.

Finally, respondents were selected through simple random sampling because it gives the whole 
population the opportunity of being selected. In selecting the sample size, the total population of the organization was taken into consideration such that a significant part of the staff strength was selected as respondents for the organization. In all, about 40 respondents were selected from the staff in different department.

Research instrument refers to the basic tools of the researcher for measuring, evaluating, analysing and exploring of data - Asika (1991). In the course of this research work, data were collected through the use of well-structured questionnaire designed well in accordance with the objectives of the study. The questionnaire made this choice of appreciable language which enables the respondents to understand the questions for appropriate response, while Likert scale and other measuring scales were used for the options.

Finally, the questionnaire was divided into two sections, that is section ' $\mathrm{A}$ ' has the demographic characteristics of respondents, and section ' $\mathrm{B}$ ' has questions that relates to the study objectives of the study.

The data were grouped using frequency distribution table, and were eventually given percentages in order to ensure further analysis of respondents' perception. In other words, the percentages gave an insight into respondents' perception in respect of the questions and responses. Hypotheses were tested using analysis of variance and other statistical drawings.

\section{RESULT AND DISCUSSION}

The following questions shall be drawn from the questionnaire for the test of hypothesis one.

Question One:

Do you use financial ratios as a measurement of management performance?

Question Two:

Do the management of this company apply financial ratios in making decisions that affect the company?

Question Four:

Do you agree that financial ratio reveal strengths and weaknesses of an organisation?

Question Ten:

Ratio Analysis is very effective at various aspect of company performance?

\section{Hypothesis One}

- H0: There is no significant relationship between ratio analysis and organisation performance.

- Hi: There is a significant relationship between ratio analysis and organisation performance.

\section{Test of hypothesis}

Data collected from respondents in questions: 1, 2, 4, and 10 shall be subjected to Fdistribution statistical method.

Data Analysis Table

\begin{tabular}{|l|l|l|l|l|l|l|}
\hline & 1 & 2 & 3 & 4 & 5 & \\
\hline 1 & 15 & 15 & 5 & 5 & - & \\
\hline 2 & 20 & 15 & 5 & - & - & \\
\hline 3 & 15 & 15 & 5 & 2 & 3 & \\
\hline 4 & 10 & 20 & 5 & - & 5 & \\
\hline 5 & 60 & 65 & 20 & 7 & 8 & $=\mathbf{1 6 0}$ \\
\hline
\end{tabular}




$$
\begin{aligned}
\mathrm{SS}_{\mathrm{T}}=\begin{array}{l}
15^{2}+15^{2}+5^{2}+5^{2}+20^{2}+15^{2} \\
+5^{2}+15^{2}+15^{2}+5^{2}+2^{2}+3^{2}-(160)^{2} \\
+10^{2}+20^{2}+5^{2}+5^{2}
\end{array} \\
\mathrm{SSC}=\begin{array}{l}
2163-1600=563 \\
60^{2}+65^{2}+20^{2}+7^{2}+8^{2}-(160)^{2} \\
5
\end{array} \\
\\
\begin{array}{ll}
1667.6-1600=667.6 \\
\mathrm{SS}_{\mathrm{E}}=
\end{array} \mathrm{SS}_{\mathrm{T}}-\mathrm{SS}_{\mathrm{C}}=104.6
\end{aligned}
$$

Other computations are shown in the table below:

\begin{tabular}{|c|c|c|c|c|}
\hline Analysis of Variance \\
\hline SOURCE OF VARIATION & DF & SS & MS & F \\
\hline Treatment & 4 & 66.7 .6 & 166.9 & \\
Error & 12 & 104.6 & 8.72 & 19.14 \\
\hline Total & 16 & 563 & & \\
\hline
\end{tabular}

$$
\begin{aligned}
& F_{\text {cal }}=19.14 \\
& F_{\text {tab }} @(0.05,4,12)=5.14
\end{aligned}
$$

\section{Decision:}

Fcal is greater than ( $>$ ) Ftab since Fcal is greater than $(>)$ Ftab, then reject null hypotheses and accept the alternative. Therefore, there is significant relationship between ratio analysis and organizational performance.

The following questions shall be drawn from the questionnaire for the test of hypothesis two (2).

Question Three:

Does ratio analysis help management in taking effective decisions?

Question Five:

Does the interpretation of rations help to determine whether the activities of the company have been effectively managed?

Question Nine:

Does the management of this company rely on financial ratios to drawn conclusion on certain issues?

Question Twelve:

Ratio analysis establishes true picture of company financial status?

\section{Hypothesis Two}

- H0: Financial ratios do not highlight the importance of effective management of an organisation.

- Hi: Financial ratios highlight the importance of effective management of an organisation.

\section{Test of hypothesis}

Data collected from respondents in questions: 3, 5, 9, and 12 shall be subjected to Fdistribution statistical method. 


$$
\begin{aligned}
& \mathrm{SS}_{\mathrm{T}}=\quad \begin{array}{l}
10^{2}+20^{2}+5^{2}+5^{2}+25^{2}+10^{2} \\
+5^{2}+15^{2}+10^{2}+5^{2}+5^{2}+5^{2}-(160)^{2}
\end{array} \\
& +5^{2}+25^{2}+10^{2}+5^{2} \\
& 2450-1706.7=743.3 \\
& \mathrm{SS}_{\mathrm{C}}=75^{2}+50^{2}+15^{2}+10^{2}+10^{2}-(160)^{2}
\end{aligned}
$$

\begin{tabular}{|l|l|l|l|l|l|l|}
\hline & $\mathbf{1}$ & $\mathbf{2}$ & $\mathbf{3}$ & $\mathbf{4}$ & $\mathbf{5}$ & \\
\hline 1 & 10 & 20 & 5 & - & 5 & \\
\hline 2 & 25 & 10 & - & 5 & - & \\
\hline 3 & 15 & 10 & 5 & 5 & 5 & \\
\hline 4 & 25 & 10 & 5 & - & - & \\
\hline 5 & 75 & 50 & 15 & 10 & 10 & $=160$ \\
\hline
\end{tabular}$$
4
$$

$2137.5-1706.7=430.8$

$\mathrm{SS}_{\mathrm{E}}=\mathrm{SS}_{\mathrm{T}}-\mathrm{SS}_{\mathrm{C}}=312.5$

Other computations are shown in the table below:

Analysis of Variance

\begin{tabular}{|c|c|c|c|c|}
\hline $\begin{array}{c}\text { Source of } \\
\text { Variation }\end{array}$ & DF & SS & MS & F \\
\hline $\begin{array}{c}\text { Treatment } \\
\text { Error }\end{array}$ & 4 & 430.8 & 107 & 79.29 \\
\hline Total & 15 & 712.5 & 28.4 & \\
\hline
\end{tabular}

$F_{\text {cal }}=79.29$

$F_{\text {tab }} @(0.05,4,11)=5.67$

\section{Decision:}

Fcal is greater than ( $>$ ) Ftab since Fcal is greater than (>) Ftab, then reject null hypotheses and accept the alternative.

Therefore, financial ratios highlight the importance of effective management of an organisation.

\section{CONCLUSION AND RECOMMENDATIONS}

This research work studied how ratio analysis can be used to measure performance of an organization. Based on the discussions and findings in the course of this study, the following conclusions are made:

- Ratio analysis is a tool of financial analysis, which can be used as a predictive tool for measuring business performance.

- Ratio analysis can be used to show areas of strengths and weaknesses of a company.

- Ratio analysis is required for management control decisions, investment decisions and credit control purposes.

- Ratio analysis is required to determine whether a company have been improving or is deteriorating financially over a period of time.

- Ratio analysis can be used to determine whether a company have met the required standard within the industry.

- Profitability ratios are useful to the management of a company. They are used to determine the profitability of a company and the efficiency in the utilization of the resources of a company. 
Therefore, the following recommendations are made:

- Ratio analysis should form part of management activities and should be computed periodically to reveal areas of strengths and weaknesses of a company.

- Ratios should be used by the management to measure the profitability of the company and to compare the financial activities of the company with that of other companies within the same industry. This helps to determine whether the company has performed up to the standard required by the industry.

- The investors should use investment ratios to determine how much divided will accrue to them.

- Creditors and loan providers are advised to check the liquidity of a company before granting loans or giving any consideration. Therefore, they should consider ratios such as current ratio and quick assets ratio.

- The employees of an organization should be interested in ratios such as the long-term solvency and liquidity ratios. This enables the employees know and measure the security of their jobs.

\section{References}

Asika, N. (1999), Research Methodology in Behavioural Science, Longman Plc, Lagos

Garbutt, D. (1972), Carter's Advanced Accounts, Sir ISAAC Pitman and Sons Ltd, London

Lucey, T. (1988), Management Accounting DP Publications Ltd London.

SAS 2 (1987), Nigerian Accounting Standard Board, PAT Publications LTD, Lagos. 